\title{
Human Occipital and Parietal GABA Selectively Influence Visual Perception of Orientation and Size
}

\author{
[Chen Song, ${ }^{1,2,3, \star}$ - Kristian Sandberg, ${ }^{1,4,5, *}$ Lau Møller Andersen, ${ }^{4,6}$ Jakob Udby Blicher, ${ }^{4}$ and $\mathbb{C G e r a i n t ~ R e e s ~}^{1,2}$ \\ ${ }^{1}$ Institute of Cognitive Neuroscience, University College London, London WC1N 3AR, United Kingdom, ${ }^{2}$ Wellcome Trust Centre for Neuroimaging, \\ University College London, London WC1N 3BG, United Kingdom, ${ }^{3}$ Department of Psychiatry, University of Wisconsin-Madison, Madison, Wisconsin \\ 53719, ${ }^{4}$ Center of Functionally Integrative Neuroscience, Aarhus University, 8000 Aarhus C, Denmark, ${ }^{5}$ Hammel Neurorehabilitation and Research Centre, \\ Aarhus University Hospital, 8450 Hammel, Denmark, and ${ }^{N}$ NatMEG, Department of Clinical Neuroscience, Karolinska Institutet, 17177 Stockholm, Sweden
}

GABA is the primary inhibitory neurotransmitter in human brain. The level of GABA varies substantially across individuals, and this variability is associated with interindividual differences in visual perception. However, it remains unclear whether the association between GABA level and visual perception reflects a general influence of visual inhibition or whether the GABA levels of different cortical regions selectively influence perception of different visual features. To address this, we studied how the GABA levels of parietal and occipital cortices related to interindividual differences in size, orientation, and brightness perception. We used visual contextual illusion as a perceptual assay since the illusion dissociates perceptual content from stimulus content and the magnitude of the illusion reflects the effect of visual inhibition. Across individuals, we observed selective correlations between the level of GABA and the magnitude of contextual illusion. Specifically, parietal GABA level correlated with size illusion magnitude but not with orientation or brightness illusion magnitude; in contrast, occipital GABA level correlated with orientation illusion magnitude but not with size or brightness illusion magnitude. Our findings reveal a region- and feature-dependent influence of GABA level on human visual perception. Parietal and occipital cortices contain, respectively, topographic maps of size and orientation preference in which neural responses to stimulus sizes and stimulus orientations are modulated by intraregional lateral connections. We propose that these lateral connections may underlie the selective influence of GABA on visual perception.

Key words: contextual modulation; GABA; individual differences; lateral connection; visual illusion

\section{Significance Statement}

GABA, the primary inhibitory neurotransmitter in human visual system, varies substantially across individuals. This interindividual variability in GABA level is linked to interindividual differences in many aspects of visual perception. However, the widespread influence of GABA raises the question of whether interindividual variability in GABA reflects an overall variability in visual inhibition and has a general influence on visual perception or whether the GABA levels of different cortical regions have selective influence on perception of different visual features. Here we report a region- and feature-dependent influence of GABA level on human visual perception. Our findings suggest that GABA level of a cortical region selectively influences perception of visual features that are topographically mapped in this region through intraregional lateral connections.

\section{Introduction}

The inhibitory neurotransmitter GABA plays a central role in visual processing ranging from neural selectivity and neural re-

Received Dec. 23, 2016; revised April 27, 2017; accepted May 3, 2017.

Author contributions: C.S., K.S., and G.R. designed research; C.S., K.S., L.M.A., and J.U.B. performed research; C.S., K.S., L.M.A., and J.U.B. contributed unpublished reagents/analytic tools; C.S., K.S., L.M.A., and J.U.B. analyzed data; C.S., K.S., L.M.A., J.U.B., and G.R. wrote the paper.

This study was supported by the Brain Research Trust (C.S.), the UNIK Program of the Danish Ministry of Science, Technology and Innovation (K.S.), and the Wellcome Trust (G.R.). We thank Dr. Jamie Near and Dr. Peter Jezzard at FMRIB (Oxford University, Oxford, UK) for providing the MRS sequence used in the current study.

${ }^{*}$ C.S. and K.S. contributed equally to this work.

The authors declare no competing financial interests. sponse gain control to synaptic plasticity and network oscillation (Priebe and Ferster, 2008; Katzner et al., 2011; Lehmann et al., 2012). The level of GABA, measured using magnetic resonance spectroscopy (MRS), varies substantially across human individuals, and this variability may contribute to interindividual differ-

Correspondence should be addressed to either of the following: Chen Song, Institute of Cognitive Neuroscience, University College London, London WC1N 3AR, UK, E-mail: chen.song.09@ucl.ac.uk; or Kristian Sandberg, Center of Functionally Integrative Neuroscience, Aarhus University, 8000 Aarhus C, Denmark, E-mail: krissand@rm.dk.

DOI:10.1523/JNEUROSCI.3945-16.2017

Copyright @ 2017 Song, Sandberg et al.

This is an open-access article distributed under the terms of the Creative Commons Attribution License Creative Commons Attribution 4.0 International, which permits unrestricted use, distribution and reproduction in any medium provided that the original work is properly attributed. 


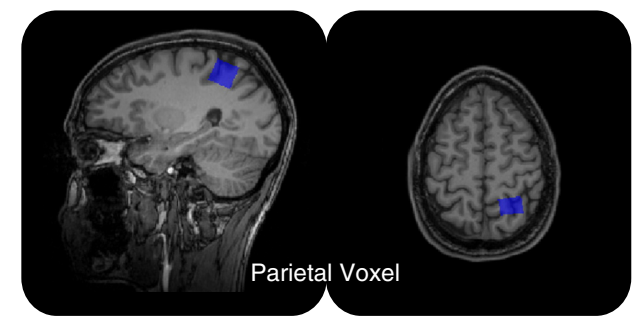

Participant 1

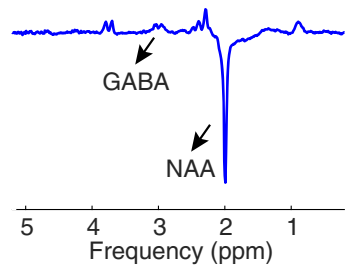

Participant 2

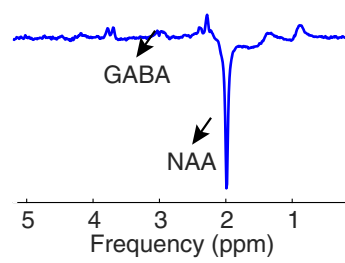

Participant 3

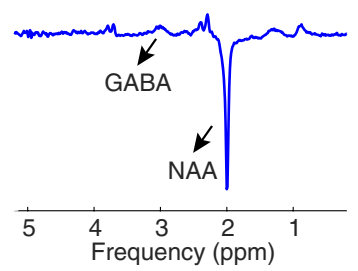

Participant 4

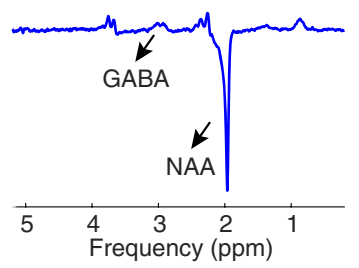

Participant 5

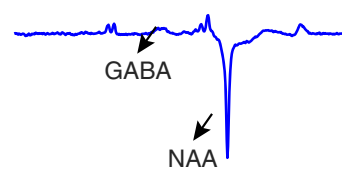

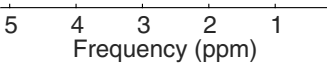

Participant 6

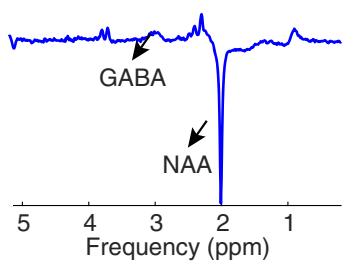

Participant 7

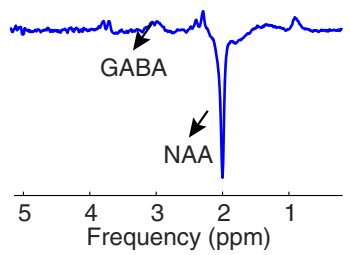

Participant 8

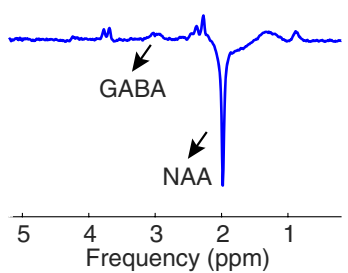

Participant 9

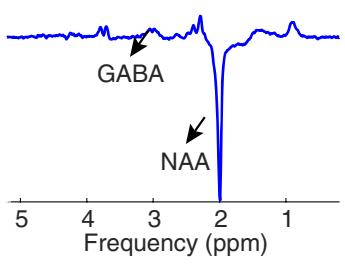

Participant 10

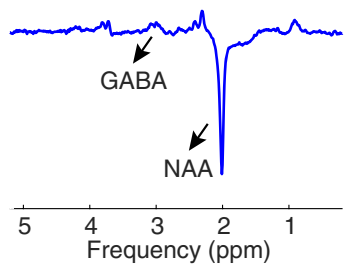

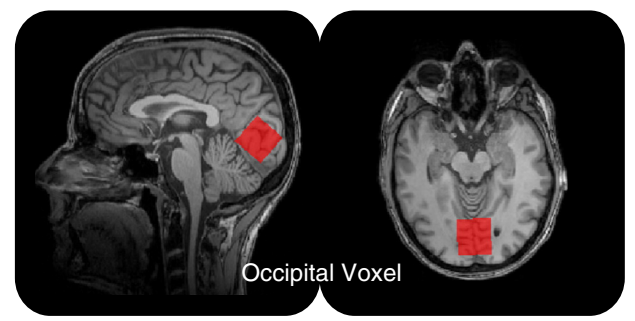

Participant 1

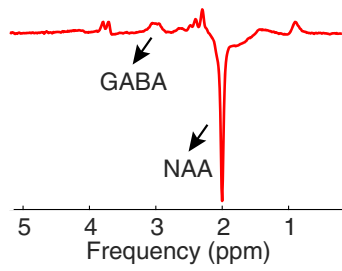

Participant 2

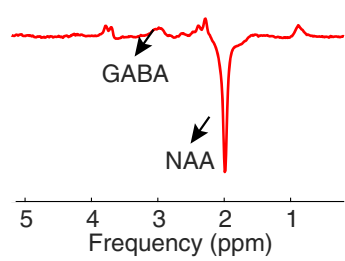

Participant 3

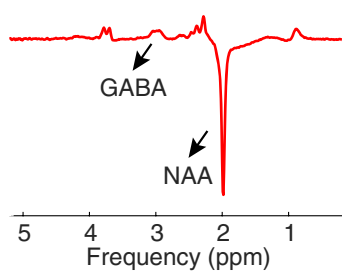

Participant 4

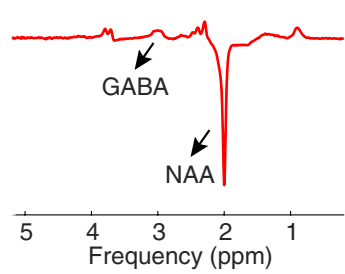

Participant 5

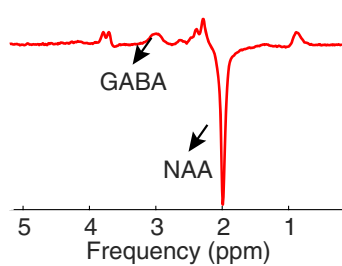

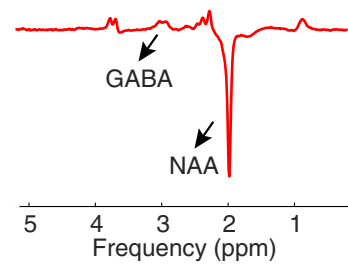

Participant 7

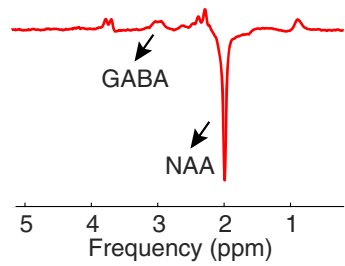

Participant 8

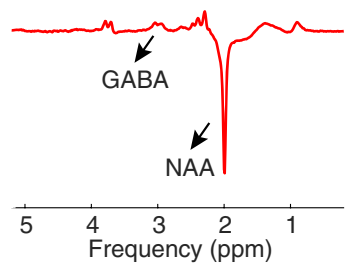

Participant 9

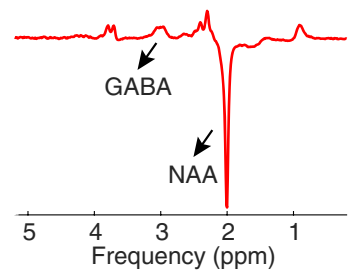

Participant 10

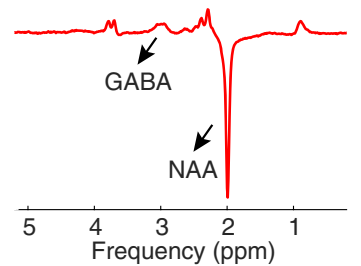

Participant 6

Figure 1. Magnetic resonance spectroscopy (MRS). In two separate experiments, MRS measure of GABA level was acquired respectively, from a parietal voxel (blue) placed on the anterior part of the superior parietal lobe with its anterior border parallel to the postcentral gyrus, and a occipital voxel (red) placed to cover the calcarine sulcus bilaterally with its anterior border in alignment with the parietal-occipital sulcus. Examples of MRS spectra from 10 randomly selected participants are shown. The GABA peak is seen at 3 ppm and the inverted NAA peak at $\sim 2$ ppm.

ences in visual processing and visual perception. Indeed, a higher GABA level is associated with higher visual discrimination ability, lower susceptibility to distraction, stronger surround suppression, and stronger interocular suppression (Edden et al., 2009; Yoon et al., 2010; van Loon et al., 2013; Sandberg et al., 2014, 2016; Lunghi et al., 2015). Moreover, in neurological disorders such as attention-deficit/ hyperactivity disorder and schizophrenia, both an abnormal level of GABA and an abnormal performance in perceptual tasks are observed (Moult, 2009; Yoon et al., 2010; Edden et al., 2012).

The widespread influence of GABA raises the question of whether interindividual variability in GABA reflects an overall variability in visual inhibition and has a general influence on 
visual perception or whether the GABA levels of different cortical regions have selective influence on perception of different visual features. One hypothesis is that the GABA level of each cortical region is uniquely determined in each individual, possibly by a combination of genetic and environmental factors (Marenco et al., 2010; Taniguchi et al., 2011; Bachtiar et al., 2015; Lunghi et al., 2015). As such, the GABA levels of different cortical regions may exhibit dissociable interindividual variability and influence perception of different visual features separately. An alternative hypothesis is that the GABA levels of different cortical regions may covary as a result of common embryonic origins or shared subcortical GABAergic projections (Dammerman et al., 2000; Jinno et al., 2007; Picardo et al., 2011; Caputi et al., 2013; Chen and Kriegstein, 2015) and may influence perception of different visual features concurrently.

To test these two alternative hypotheses, we studied how the GABA levels of parietal and occipital cortices related to interindividual differences in size, orientation, and brightness perception. Occipital cortex contains a map of orientation preference in which individual neurons respond preferentially to specific orientation and neighboring neurons to adjacent orientations; by contrast, parietal cortex contains a map of size preference in which individual neuronal populations respond preferentially to specific size of a visually presented object and neighboring neurons to adjacent sizes (Yacoub et al., 2008; Harvey et al., 2015). Since neurotransmitters are contained and released at synapses, the GABA level of a cortical region may influence visual perception through synaptic connections within the region, which link neighboring neurons of similar feature preferences. These intraregional lateral connections underlie contextual illusions where the perceived feature (e.g., orientation, size) of a visual stimulus is modulated by the stimulus surrounding it (Cannon and Fullenkamp, 1996; Kapadia et al., 2000; Stettler et al., 2002; Bosten and Mollon, 2010; Song et al., 2013a). We therefore used contextual illusion as a perceptual assay, hypothesizing that selective correlation may be observed between the GABA level of a cortical region and the contextual illusion for visual features topographically mapped in this cortical region. Specifically, parietal and occipital GABA levels may correlate selectively with the magnitude of size and orientation illusion.

\section{Materials and Methods}

Participants. Thirty-seven healthy volunteers (age range, $20-40$ years; all males; females were ineligible due to the menstrual cycle) gave written informed consent to participate in this study that was approved by the local ethics committee, De Videnskabsetiske Komitéer for Region Midtjylland, Denmark. All participants had normal or corrected-tonormal vision and no neurological or psychiatric history. The MRS data of four participants were contaminated by the signal from lipids, and the psychophysics data of three participants were outliers of the normal distribution (Shapiro-Wilk test). These data were therefore excluded from further analysis.

Magnetic resonance spectroscopy (MRS) measure of GABA. Neuroimaging experiments took place in a Siemens Trio 3T MRI scanner. Structural MRI data were acquired using a T1-weighted MPRAGE sequence (TR, 2420 $\mathrm{ms}$; TE, $3.7 \mathrm{~ms}$; resolution, $1 \mathrm{~mm}$ isotropic; scanning time, $5.5 \mathrm{~min}$ ) and were used to guide the voxel placement in MRS. Resting GABA measures were acquired respectively from a $2 \mathrm{~cm}$ isotropic voxel in the parietal lobe (TR, $2500 \mathrm{~ms}$; TE, $68 \mathrm{~ms} ; 240$ edit on and edit off averages; scan time, 20 $\mathrm{min}$ ) and a $3 \mathrm{~cm}$ isotropic voxel in the occipital lobe (TR, $2500 \mathrm{~ms}$; TE, 68 ms; 96 edit on and edit off averages; scan time, 8 min) using MEGAPRESS method (Mescher et al., 1998; Edden and Barker, 2007). To compensate for the size differences between the two voxels, the parietal voxel had a longer scan time (20 $\mathrm{min})$ than the occipital voxel ( $8 \mathrm{~min})$. An even longer scan time (40 min) could lead to a better compensation; however,

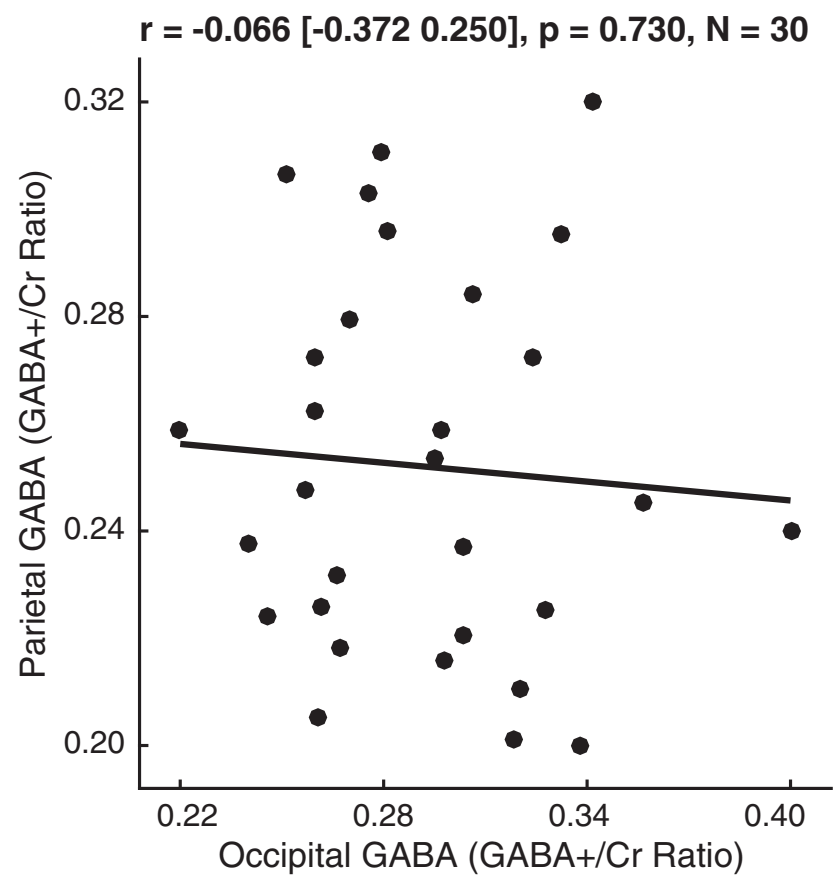

Figure 2. Parietal and occipital GABA. The GABA levels of parietal and occipital cortices were plotted against each other, illustrating a lack of interindividual correlation between the two variables. Each data point represents a participant. Statistical values reflect Pearson's correlation coefficient and $95 \%$ bootstrap confidence interval.

the subject motion would be a drawback. The MRS measure of resting GABA varies little across days or even months (Evans et al., 2010; Near et al., 2014). The high test-retest reliability suggests that the scanning order will not bias the measures. Nevertheless, to minimize the betweensubject variance of no interest, we kept the scanning order identical for all participants, collecting data for the occipital voxel first and the parietal voxel second. The parietal voxel was placed on the anterior part of the superior parietal lobe with its anterior border in parallel with the postcentral gyrus. The occipital voxel was placed to cover the calcarine sulcus bilaterally with its anterior border in alignment with the parietal-occipital sulcus. Care was taken to avoid the inclusion of the scalp and/or the tentorium cerebelli in the voxels.

The MEGA-PRESS method measures the level of GABA through the acquisition of the following two spectra: one with an editing pulse targeting the C3-GABA peak at $1.9 \mathrm{ppm}$ (edit on); and one with an editing pulse targeting the water peak on the symmetrical side at $7.5 \mathrm{ppm}$ (edit off). By averaging the two spectra, the creatine (Cr) peak at $3.0 \mathrm{ppm}$ was quantified. By subtracting the two spectra, the C4-GABA peak at $3 \mathrm{ppm}$ was quantified. This $\mathrm{C} 4-\mathrm{GABA}$ peak is often referred to as $\mathrm{GABA}^{+}$, since a coupled macromolecule (MM) resonance at $3 \mathrm{ppm}$ is coedited and contributes to the measured signal. Due to the limitation of the MEGAPRESS sequence, the exact MM contribution is difficult to estimate or remove. A theoretical model has been proposed to subtract MM contribution post hoc (Murdoch and Dydak, 2011). Nevertheless, this technique could introduce additional variability into the estimated GABA values and is thus rarely used (Mullins et al., 2014, their discussion). Newer sequences such as MEGA-SPECIAL (Near et al., 2011) and SPECIAL (Near et al., 2013) aim to remove MM contribution by editing and modeling, respectively. However, both sequences have other drawbacks such as the imperfect lipid suppression. The raw GABA value is subject to bias from day-to-day scanner-related variation. For an unbiased estimate of GABA, a normalization of raw GABA value to $\mathrm{Cr}$ is typically applied (Mullins et al., 2014), since Cr resonates around the same frequency (3 ppm) as GABA and is not affected by disturbances that depend on the resonance frequency. The ratio $\mathrm{GABA}^{+} / \mathrm{Cr}$ was calculated to quantify GABA level.

The analysis of MRS data was performed by author J.U.B., who was blind to the psychophysics data, and the analysis constituted part of a 

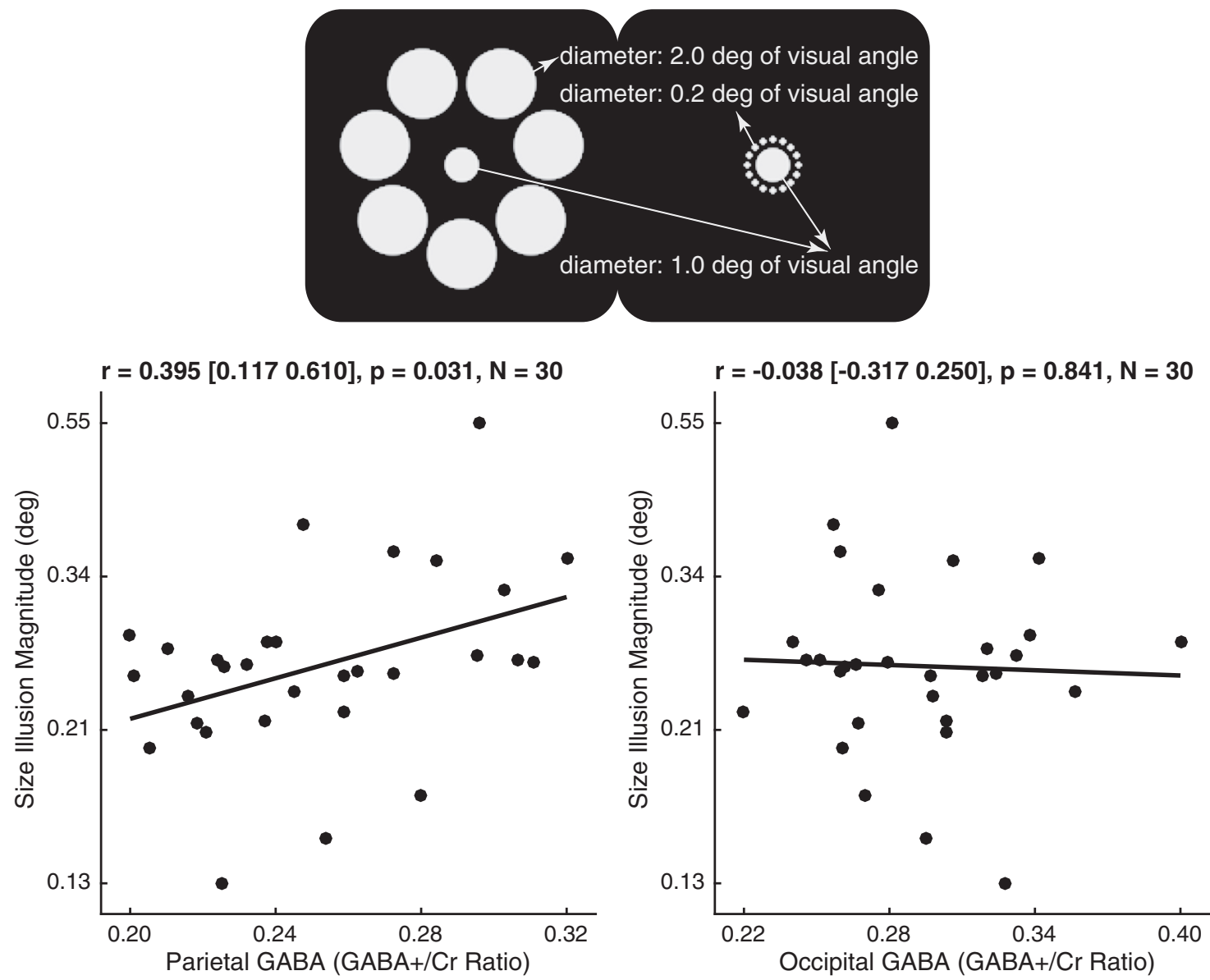

Figure 3. GABA level and size illusion. In the Ebbinghaus illusion, two physically identical central circles appear to have different perceived sizes as a result of the surrounding context of either smaller or larger circles. The magnitude of the Ebbinghaus illusion for each participant was plotted in semi-log graph against their parietal or occipital GABA level, illustrating a positive correlation between size illusion magnitude and parietal GABA level, as well as a lack of significant correlation between size illusion magnitude and occipital GABA level. Each data point represents a participant. Statistical values reflect Pearson's correlation coefficient and 95\% bootstrap confidence interval.

database that have been reported in previous studies (Near et al., 2014; Sandberg et al., 2014, 2016;). The MRS data were first preprocessed in MATLAB with FID-A software for motion corruption removal, drift correction, and phasing, and then were analyzed in jMRUI software with the AMARES package (Mescher et al., 1998; Edden and Barker, 2007; Simpson et al., 2017). Data were visually inspected for noise, line broadening, voxel misplacement, and lipid contamination. Four participants who had spectra with large lipid contamination failed to pass the visual inspection and were excluded from further analysis. The quality of the included spectra was evaluated by calculating signal-to-noise ratio (SNR), line width, and fit uncertainty. Examples of typical spectra are shown in Figure 1 . SNR was calculated using the difference spectrum following the phase adjustment such that the $N$-acetylaspartate (NAA) peak was upright with a phase of $0^{\circ}$. The signal was calculated as the maximal intensity of the NAA peak in the difference spectrum; noise was calculated as the SD of the noise in the signal-free spectrum following a baseline correction to remove any first- and second-order baseline variations. The SNR was 108 for the parietal voxel and 226 for the occipital voxel. Line width was calculated by measuring the full-width at half-maximum of the NAA peak in the difference spectrum. The mean line width was $4.8 \mathrm{~Hz}$ for the parietal voxel and $5.4 \mathrm{~Hz}$ for the occipital voxel. Fit uncertainty was measured as the SD/amplitude ratio output by jMRUI. The mean SD/amplitude ratio was 0.04 for the parietal voxel and 0.03 for the occipital voxel.

Psychophysics measure of contextual illusion. Psychophysics experiments took place in a dark room. Visual stimuli were presented on a 17 inch LCD monitor (spatial resolution, $1024 \times 768$ pixels; temporal resolution, $60 \mathrm{~Hz}$ ) and viewed through a chin rest. The magnitudes of size illusion (Ebbinghaus illusion), orientation illusion (tilt illusion), and brightness illusion (simultaneous contrast illusion) were measured in separate experiments. The size illusion stimulus comprised two white circles $\left(1^{\circ}\right.$ diameter), a reference circle surrounded by 16 small white circles $\left(0.2^{\circ}\right.$ diameter $)$ and a test circle by seven large white circles $\left(2^{\circ}\right.$ diameter), that were presented simultaneously for $500 \mathrm{~ms}$ on two sides of the fixation (3.85 eccentricity) with randomized spatial order. The orientation illusion stimulus comprised two circular gratings $\left(45^{\circ}\right.$ orientation, $1.5^{\circ}$ diameter, 2.5 cycles $/{ }^{\circ}$ spatial frequency, $100 \%$ contrast), a reference grating surrounded by an annular grating $\left(60^{\circ}\right.$ orientation, $4.5^{\circ}$ diameter, 2.5 cycles $/{ }^{\circ}$ spatial frequency, $100 \%$ contrast) and a test grating with no surround. The brightness illusion stimulus comprised two gray circles ( $50 \%$ luminance, $1.5^{\circ}$ diameter), a reference circle surrounded by a white annulus $\left(4.5^{\circ}\right.$ diameter $)$ and a test circle by a black annulus $\left(4.5^{\circ}\right.$ diameter).

To minimize the confounding factors such as decision factors (Vogels and Orban, 1986; Gold and Ding, 2012), we kept the psychophysical procedures identical for all three illusions. Participants first performed a match-to-standard session in which they manually adjusted the size, orientation, or luminance of the test stimulus until it matched the perceived size, orientation, or luminance of the reference stimulus, and a visual discrimination session in which the size, orientation, and luminance discrimination threshold was measured through standard 2-up-1down staircase procedures. The point of subjective equality measured from the match-to-standard session and the visual discrimination threshold measured from the staircase session were used to guide the choices of stimulus parameters in the subsequent two-alternative forcedchoice session. There, participants were asked on 112 trials to judge 

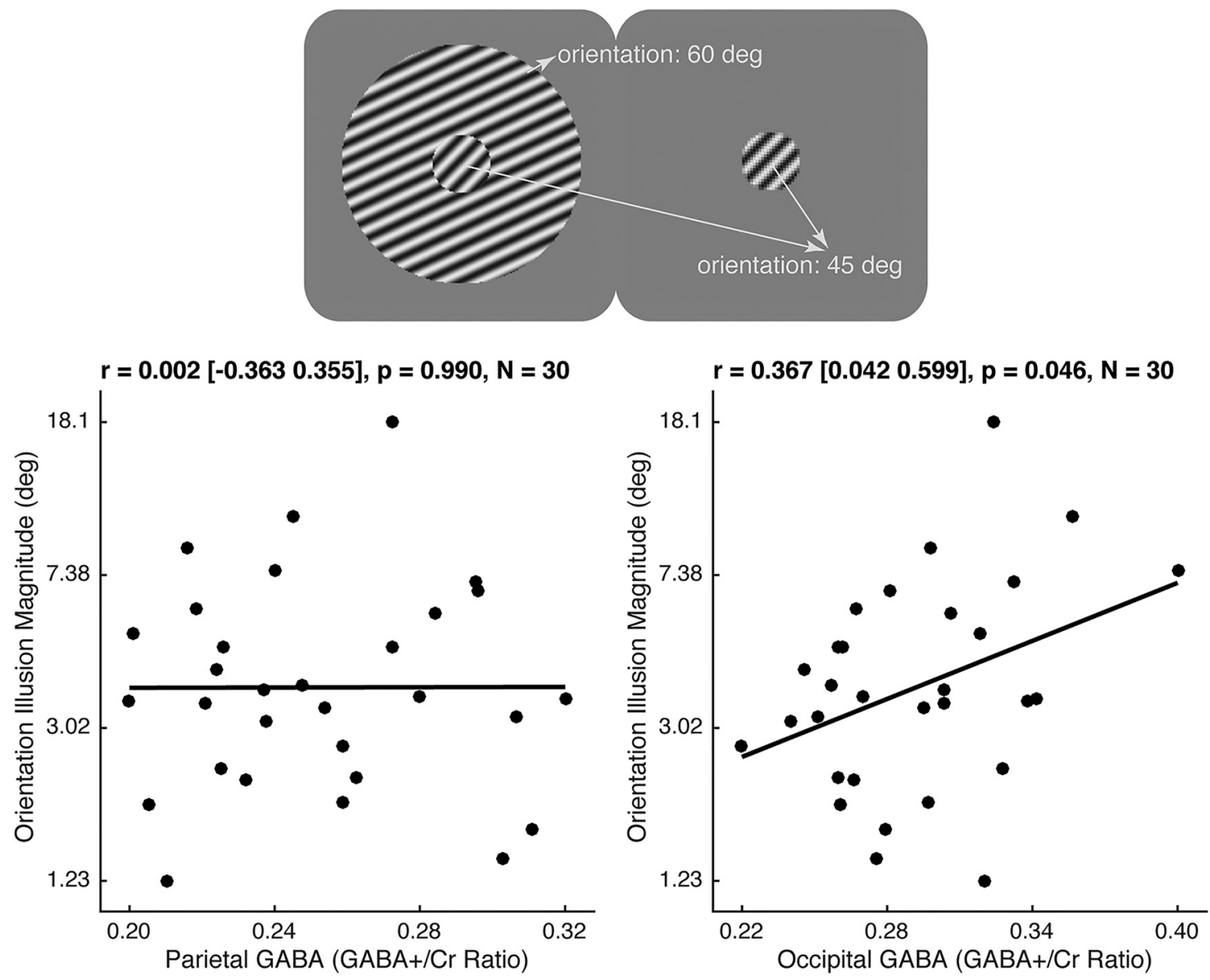

Figure 4. GABA and orientation illusion. In the tilt illusion, two physically identical central gratings appear to have different perceived orientations as a result of their immediate surroundings. The magnitude of the tilt illusion for each participant was plotted in semi-log graph against their parietal or occipital GABA level, illustrating a positive correlation between orientation illusion magnitude and occipital GABA level, as well as a lack of significant correlation between orientation illusion magnitude and parietal GABA level. Each data point represents a participant. Statistical values reflect Pearson's correlation coefficient and $95 \%$ bootstrap confidence interval.

which central stimulus was larger (for size illusion), more tilted (for orientation illusion), or brighter (for brightness illusion). The size, orientation, or luminance of the reference stimulus was kept constant; that of the test stimulus was varied among seven values (16 trials per value) around the point of subjective equality acquired from the match-tostandard session, with a step size equal to the visual discrimination threshold.

The data from the two-alternative forced-choice session were fitted with psychometric function to measure the $50 \%$ threshold point where the two central stimuli appeared perceptually equal despite their physical difference. The goodness of fit $\left(R^{2}\right)$ was $0.963 \pm 0.033$ for orientation illusion, $0.956 \pm 0.041$ for size illusion, and $0.960 \pm 0.033$ for brightness illusion. The goodness of fit did not differ significantly between illusions (size illusion vs orientation illusion: $t_{(29)}=1.03, p=0.313$; size illusion vs brightness illusion: $t_{(29)}=0.47, p=0.640$; orientation illusion vs brightness illusion: $t_{(29)}=0.28, p=0.785$ ) or correlate significantly with GABA (size illusion and parietal GABA: $r=-0.194, p=0.304$; size illusion and occipital GABA: $r=0.143, p=0.451$; orientation illusion and parietal GABA: $r=0.244, p=0.194$; orientation illusion and occipital GABA: $r=0.142, p=0.456$; brightness illusion and parietal GABA: $r=-0.224, p=0.234$; brightness illusion and occipital GABA: $r=0.174, p=0.359$ ). The physical difference between the two central stimuli at the $50 \%$ threshold point was calculated to quantify the illusion magnitude.

To account for the influence of Weber's law (Shen, 2003), we used the $\log$ transform of the illusion magnitude and the semi-log plots (see Figs. $3,4,5)$ to assess interindividual differences. Since the magnitude of orientation illusion is subject to the oblique effect (Clifford, 2014), we per- formed additional control experiments in a group of 20 healthy volunteers (age range, 21-35 years; 11 females) to test the influence of stimulus orientation (cardinal vs oblique) on the measure of interindividual differences. We found that although the illusion magnitude was weaker for the cardinal condition than the oblique condition $\left(t_{(19)}=\right.$ 20.362, $p<10^{-13}$ ), the illusion magnitude was highly correlated between the two conditions $\left(r=0.866, p<10^{-6}\right)$. This observation suggested that interindividual differences in orientation illusion magnitude were not biased by the oblique effect.

Statistics. Pearson's correlation can capture the linearity in the relation between two variables, whereas Spearman's rank correlation can only reflect whether two variables are monotonically related or not. For example, Spearman's correlation coefficient will return the same result of 1 for two variables that both monotonically increase, regardless of whether their rates of increase are linearly or nonlinearly correlated; by contrast, Pearson's correlation coefficient can capture the difference between these two conditions. As such, Pearson's correlation coefficient is a more suitable test for comparing the correlation coefficient between different experimental conditions. Application of Pearson's correlation requires the data to satisfy normal distribution. The Shapiro-Wilk test failed to refute the assumption of normality for parietal GABA level [coefficient of concordance $(\mathrm{W})=0.952, p=0.187]$, occipital GABA level $(\mathrm{W}=0.962, p=$ $0.295)$, size illusion magnitude $(\mathrm{W}=0.937, p=0.072$ ), orientation illusion magnitude $(\mathrm{W}=0.985, p=0.942)$, or brightness illusion magnitude $(\mathrm{W}=0.960, p=0.314$ ). Therefore, Pearson's correlation was used throughout this study to test the relations between variables, with age regressed out. 

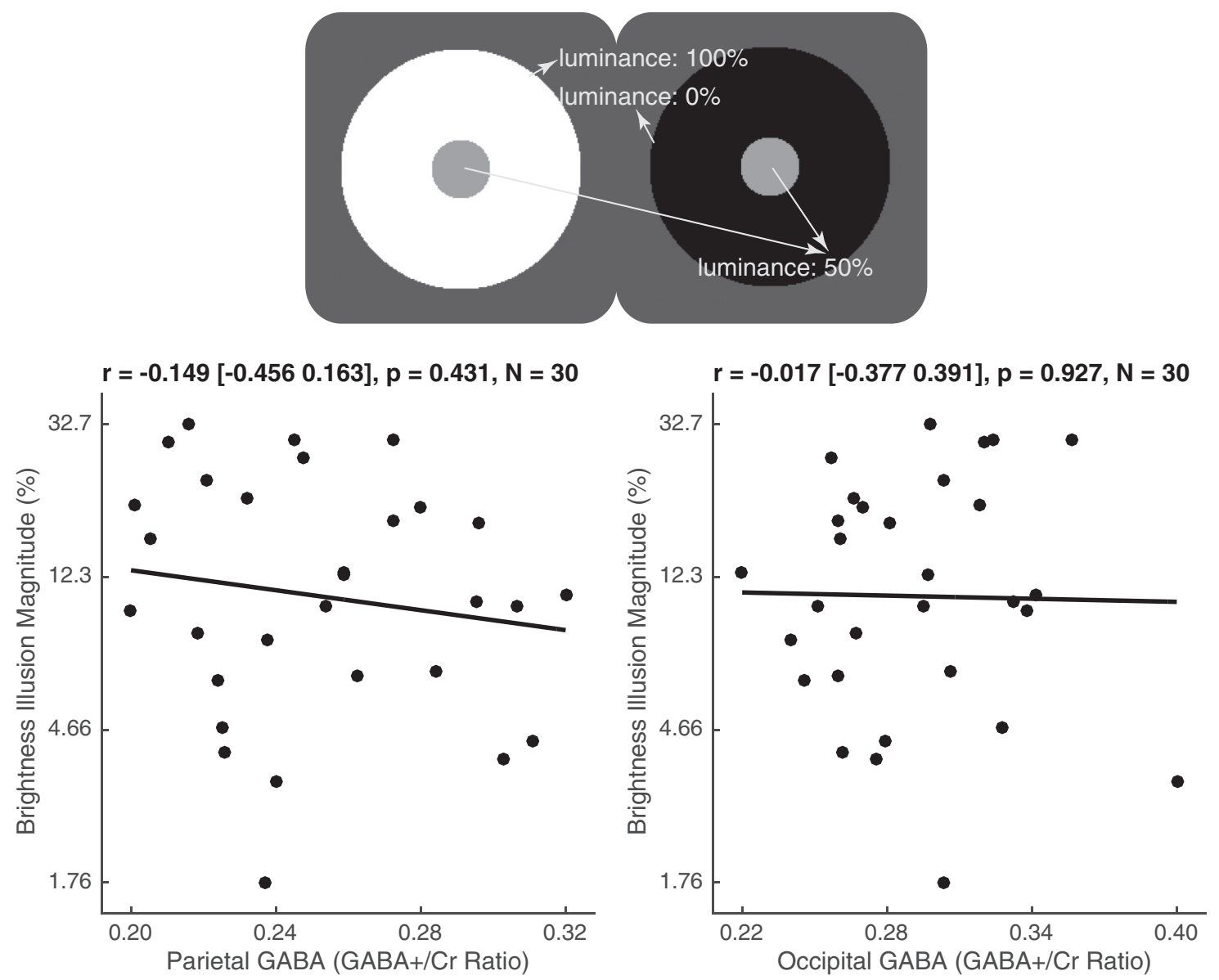

Figure 5. GABA level and brightness illusion. In the simultaneous contrast illusion, two physically identical central circles appear to have different brightness as a result of their immediate surroundings. The magnitude of simultaneous contrast illusion for each participant was plotted in semi-log graph against their parietal or occipital GABA level, illustrating a lack of significant correlation between brightness illusion magnitude and either parietal or occipital GABA level. Each data point represents a participant. Statistical values reflect Pearson's correlation coefficient and $95 \%$ bootstrap confidence interval.

\section{Results}

We found that the GABA level in parietal cortex $(0.252 \pm 0.035)$ and the GABA level in occipital cortex $(0.299 \pm 0.042)$ exhibited dissociated interindividual variability [Fig. 2; $r=-0.066(95 \%$ CI, -0.372 to 0.250$) ; p=0.730, N=30]$. Subsequently, we studied how parietal GABA level versus occipital GABA level contributed to interindividual differences in size illusion (Ebbinghaus illusion), orientation illusion (tilt illusion), and brightness illusion (simultaneous contrast illusion).

Across individuals, we observed a positive correlation between the magnitude of size illusion and the level of parietal GABA [Fig. $3 ; r=0.395$ (95\% CI, 0.117-0.610); $p=0.031, N=30$ ]. By contrast, we did not observe any significant correlation between the magnitude of size illusion and the level of occipital GABA [Fig. 3; $r=-0.038$ (95\% CI, -0.317 to 0.250$) ; p=0.841, N=$ 30]. Moreover, compared with occipital GABA level, parietal GABA level showed a significantly higher correlation with size illusion magnitude $\left(t_{(27)}=2.369, p=0.018\right)$. These results suggest a selective correlation between size illusion and parietal GABA.

Conversely, across individuals, the magnitude of orientation illusion exhibited a positive correlation with the level of occipital GABA [Fig. 4; $r=0.367$ (95\% CI, 0.042-0.599); $p=0.046, N=$ 30 ], but not with the level of parietal GABA [Fig. $4 ; r=0.002$ (95\% CI, -0.363 to 0.355$) ; p=0.990, N=30$ ]. Moreover, occipital GABA level had a significantly greater correlation with orientation illusion magnitude than did parietal GABA level $\left(t_{(27)}=1.990, p=0.047\right)$. These results suggest a selective correlation between orientation illusion and occipital GABA.

For the brightness illusion, we did not observe any significant correlation across individuals between the illusion magnitude and parietal GABA level [Fig. 5; $r=-0.149$ (95\% CI, -0.456 to $0.163) ; p=0.431, N=30$ ] or occipital GABA level [Fig. $5 ; r=$ -0.017 (95\% CI, -0.377 to 0.391$) ; p=0.927, N=30]$. Accordingly, the correlation between parietal GABA level and brightness illusion magnitude was not significantly different from the correlation between occipital GABA level and brightness illusion magnitude $\left(t_{(27)}=0.690, p=0.490\right)$.

\section{Discussion}

Together, our study reveals a region- and feature-dependent influence of neurotransmitter level on human visual perception. We show that interindividual variability in parietal GABA level correlated with size illusion magnitude but not with orientation or brightness illusion magnitude; in contrast, interindividual variability in occipital GABA level correlated with orientation illusion magnitude but not with size or brightness illusion magnitude. Our findings suggest that interindividual variability in GABA does not reflect a general variability in visual inhibition; instead, the GABA levels of different cortical regions have selective influence on perception of different visual features. This influence is likely to be exerted through 
lateral connections within the cortical region and is observed specifically for visual features mediated by such connections.

In occipital cortex, neurons exhibit orientation preference such that their response is the strongest for a preferred orientation and gradually decays as the stimulus orientation deviates from this preferred orientation (Ringach et al., 2002). Neurons preferring adjacent orientations are cortically adjacent to one another and are connected by intraregional lateral connections (Yacoub et al., 2008; Bock et al., 2011; Li et al., 2012). This topographical organization of lateral connections allows the orientation preference of neurons to be modulated by the activity of their adjacent neurons and the level of occipital GABA to affect the degree of modulation (Burr et al., 1981; Morrone et al., 1987; Eysel et al., 1990; Gilbert et al., 1996; Fitzpatrick, 2000; Stettler et al., 2002; Smith et al., 2006; Chavane et al., 2011). This neural-level modulation may then give rise to perceptual-level modulation, where the perceived orientation of a stimulus is modulated by the orientation of the stimulus surrounding it (Schwartz et al., 2007; Song et al., 2013a). If so, the correlation between the magnitude of orientation illusion and the level of occipital GABA could be a perceptual reflection of the GABA influence on neural orientation preference.

Whereas orientation preference is topographically mapped in occipital cortex with neurons preferring more similar orientations being more highly connected, there is no topographic map of size preference in occipital cortex (Swindale, 2000; Chklovskii and Koulakov, 2004). As such, a local GABA influence, exerted through lateral connections within occipital cortex, is likely to be specific to orientation illusion and not generalizable to size illusion. Just as the topographic map of orientation preference is prominent in occipital cortex (Wolf and Geisel, 1998; Yacoub et al., 2008; Kaschube et al., 2010), a topographic map of size preference exists in parietal cortex where individual neuronal populations respond preferentially to a specific size and adjacent neurons respond to adjacent sizes (Harvey et al., 2015). By contrast, there is no map of orientation preference in parietal cortex. Therefore, a local GABA influence, exerted through lateral connections within parietal cortex, would be specific to size illusion and not generalizable to orientation illusion. Similar to the orientation preference and size preference in cortical neurons, neurons in the retina exhibit preference for stimulus luminance and are topographically connected by their luminance preference. Possibly, the interindividual differences in brightness illusions may associate with interindividual variability in retinal GABA (Lukasiewicz and Shields, 1998; Wu, 2010). Moreover, since neural responses to visual features are modulated not only by intraregional lateral connections but also by inter-regional feedback connections (Fitzpatrick, 2000; Smith et al., 2006), the lack of correlation between brightness illusion and occipital or parietal GABA level could also indicate a predominant contribution of inter-regional (as opposed to intraregional) factors to this illusion (Kinoshita and Komatsu, 2001; Perna et al., 2005).

This proposal, that the GABA level of a cortical region influences perception of visual features topographically mapped in this region, would be able to explain the reported correlations between occipital GABA level and orientation discrimination threshold (Edden et al., 2009). The intraregional modulation exerted through lateral connections may not only shift neural orientation preference and give rise perceptual shifts in orientation illusion, but also sharpen neural orientation preference (orientation tuning) and give rise to perceptual sharpening in orientation discrimination (Ben-Yishai et al., 1995; Somers et al., 1995; Orban and Vogels, 1998; Song et al., 2013b; Song et al.,
2015). As such, the influence of occipital GABA level on orientation illusion could be mirrored in orientation discrimination (Song et al., 2013b). In addition to orientation preference, ocular preference is also topographically mapped in occipital cortex, where individual neurons respond preferentially to stimulus from a specific eye and adjacent neurons to opposite eyes (Menon et al., 1997; Dechent and Frahm, 2000; Adams et al., 2007). There, lateral connections would link neurons with opposite ocular preference, allowing the GABA influence on orientation perception to generalize to binocular perception. This would explain the reported decrease in both occipital GABA level and interocular suppression after monocular deprivation (Lunghi et al., 2015).

Our proposal, that the GABA level of a cortical region influences perception of visual features topographically mapped in this region, further predicts a correlation between parietal GABA and numerosity perception. Just as occipital cortex is crucial for processing low-level visual features and contains maps of orientation preference and ocular preference, parietal cortex is important for processing high-level visual features and contains maps of size preference and numerosity preference (Walsh, 2003; Chklovskii and Koulakov, 2004; Pinel et al., 2004; Dehaene and Cohen, 2007; Roitman et al., 2007; Dormal et al., 2008; Bueti and Walsh, 2009; Cohen Kadosh and Walsh, 2009; Nieder and Dehaene, 2009; Roitman et al., 2012; Harvey et al., 2013; Harvey et al., 2015). The lateral connections in parietal cortex are likely to link neighboring neurons with similar numerosity preference, which would allow parietal GABA to influence numerosity discrimination and numerosity illusion (Pinel et al., 2004; Almeida et al., 2007; Dormal et al., 2008; Bosten and Mollon, 2010). While the posterior part of the cortex (e.g., occipital cortex, parietal cortex) is involved in sensory processing, a topographic map of conceptual knowledge was discovered in prefrontal cortex, suggesting a potential role of frontal GABA in conceptual categorization (Constantinescu et al., 2016). It would thus be of interest for future studies to test the links between parietal GABA and numerosity perception, or between frontal GABA and conceptual categorization.

\section{References}

Adams DL, Sincich LC, Horton JC (2007) Complete pattern of ocular dominance columns in human primary visual cortex. J Neurosci 27:1039110403. CrossRef Medline

Almeida A, Arantes J, Machado A (2007) Numerosity discrimination in preschool children. J Exp Anal Behav 88:339-354. CrossRef Medline

Bachtiar V, Near J, Johansen-Berg H, Stagg CJ (2015) Modulation of GABA and resting state functional connectivity by transcranial direct current stimulation. Elife 4:e08789. CrossRef Medline

Ben-Yishai R, Bar-Or RL, Sompolinsky H (1995) Theory of orientation tuning in visual cortex. Proc Natl Acad Sci U S A 92:3844-3848. CrossRef Medline

Bock DD, Lee WC, Kerlin AM, Andermann ML, Hood G, Wetzel AW, Yurgenson S, Soucy ER, Kim HS, Reid RC). (2011) Network anatomy and in vivo physiology of visual cortical neurons. Nature 471:177-182. CrossRef Medline

Bosten JM, Mollon JD (2010) Is there a general trait of susceptibility to simultaneous contrast? Vision Res 50:1656-1664. CrossRef Medline

Bueti D, Walsh V (2009) The parietal cortex and the representation of time, space, number and other magnitudes. Philos Trans R Soc Lond B Biol Sci 364:1831-1840. CrossRef Medline

Burr D, Morrone C, Maffei L (1981) Intra-cortical inhibition prevents simple cells from responding to textured visual patterns. Exp Brain Res 43: 455-458. Medline

Cannon MW, Fullenkamp SC (1996) A model for inhibitory lateral interaction effects in perceived contrast. Vision Res 36:1115-1125. CrossRef Medline

Caputi A, Melzer S, Michael M, Monyer H (2013) The long and short of GABAergic neurons. Curr Opin Neurobiol 23:179-186. CrossRef Medline

Chavane F, Sharon D, Jancke D, Marre O, Frégnac Y, Grinvald A (2011) 
Lateral spread of orientation selectivity in $\mathrm{V} 1$ is controlled by intracortical cooperativity. Front Syst Neurosci 5:4. CrossRef Medline

Chen J, Kriegstein AR (2015) A GABAergic projection from the zona incerta to cortex promotes cortical neuron development. Science 350:554-558. CrossRef Medline

Chklovskii DB, Koulakov AA (2004) Maps in the brain: what can we learn from them? Annu Rev Neurosci 27:369-392. CrossRef Medline

Clifford CW (2014) The tilt illusion: phenomenology and functional implications. Vision Res 104:3-11. CrossRef Medline

Cohen Kadosh R, Walsh V (2009) Numerical representation in the parietal lobes: abstract or not abstract? Behav Brain Sci 32:313-328. CrossRef Medline

Constantinescu AO, O'Reilly JX, Behrens TEJ (2016) Organizing conceptual knowledge in humans with a gridlike code. Science 352:1464-1468. CrossRef Medline

Dammerman RS, Flint AC, Noctor S, Kriegstein AR (2000) An excitatory GABAergic plexus in developing neocortical layer 1. J Neurophysiol 84: 428-434. Medline

Dechent P, Frahm J (2000) Direct mapping of ocular dominance columns in human primary visual cortex. Neuroreport 11:3247-3249. CrossRef Medline

Dehaene S, Cohen L (2007) Cultural recycling of cortical maps. Neuron 56:384-398. CrossRef Medline

Dormal V, Andres M, Pesenti M (2008) Dissociation of numerosity and duration processing in the left intraparietal sulcus: a transcranial magnetic stimulation study. Cortex 44:462-469. CrossRef Medline

Edden RA, Barker PB (2007) Spatial effects in the detection of $\gamma$-aminobutyric acid: improved sensitivity at high fields using inner volume saturation. Magn Reson Med 58:1276-1282. CrossRef Medline

Edden RA, Muthukumaraswamy SD, Freeman TC, Singh KD (2009) Orientation discrimination performance is predicted by GABA concentration and gamma oscillation frequency in human primary visual cortex. J Neurosci 29:15721-15726. CrossRef Medline

Edden RA, Crocetti D, Zhu H, Gilbert DL, Mostofsky SH (2012) Reduced GABA concentration in attention-deficit/hyperactivity disorder. Arch Gen Psychiatry 69:750-753. CrossRef Medline

Evans CJ, McGonigle DJ, Edden RA (2010) Diurnal stability of $\gamma$-aminobutyric acid concentration in visual and sensorimotor cortex. J Magn Reson Imaging 31:204-209. CrossRef Medline

Eysel UT, Crook JM, Machemer HF (1990) GABA-induced remote inactivation reveals cross-orientation inhibition in the cat striate cortex. Exp Brain Res 80:626-630. Medline

Fitzpatrick D (2000) Seeing beyond the receptive field in primary visual cortex. Curr Opin Neurobiol 10:438-443. CrossRef Medline

Gilbert CD, Das A, Ito M, Kapadia M, Westheimer G (1996) Spatial integration and cortical dynamics. Proc Natl Acad Sci U S A 93:615-622. CrossRef Medline

Gold JI, Ding L (2013) How mechanisms of perceptual decision-making affect the psychometric function. Prog Neurobiol 103:98-114. CrossRef Medline

Harvey BM, Klein BP, Petridou N, Dumoulin SO (2013) Topographic representation of numerosity in the human parietal cortex. Science 341 : 1123-1126. CrossRef Medline

Harvey BM, Fracasso A, Petridou N, Dumoulin SO (2015) Topographic representations of object size and relationships with numerosity reveal generalized quantity processing in human parietal cortex. Proc Natl Acad Sci U S A 112:13525-13530. CrossRef Medline

Ikeda K, Bekkers JM (2009) Counting the number of releasable synaptic vesicles in a presynaptic terminal. Proc Natl Acad Sci U S A 106:29452950. CrossRef Medline

Jinno S, Klausberger T, Marton LF, Dalezios Y, Roberts JD, Fuentealba P, Bushong EA, Henze D, Buzsáki G, Somogyi P (2007) Neuronal diversity in GABAergic long-range projections from the hippocampus. J Neurosci 27:8790-8804. CrossRef Medline

Kapadia MK, Westheimer G, Gilbert CD (2000) Spatial distribution of contextual interactions in primary visual cortex and in visual perception. J Neurophysiol 84:2048-2062. Medline

Kaschube M, Schnabel M, Löwel S, Coppola DM, White LE, Wolf F (2010) Universality in the evolution of orientation columns in the visual cortex. Science 330:1113-1116. CrossRef Medline

Katzner S, Busse L, Carandini M (2011) $\mathrm{GABA}_{\mathrm{A}}$ inhibition controls response gain in visual cortex. J Neurosci 31:5931-5941. CrossRef Medline
Kinoshita M, Komatsu H (2001) Neural representation of the luminance and brightness of a uniform surface in the macaque primary visual cortex. J Neurophysiol 86:2559-2570. Medline

Lehmann K, Steinecke A, Bolz J (2012) GABA through the ages: regulation of cortical function and plasticity by inhibitory interneurons. Neural Plast 2012:892784. CrossRef Medline

Li Y, Lu H, Cheng PL, Ge S, Xu H, Shi SH, Dan Y (2012) Clonally related visual cortical neurons show similar stimulus feature selectivity. Nature 486:118-121. CrossRef Medline

Lukasiewicz PD, Shields CR (1998) A diversity of GABA receptors in the retina. Semin Cell Dev Biol 9:293-299. CrossRef Medline

Lunghi C, Emir UE, Morrone MC, Bridge H (2015) Short-term monocular deprivation alters GABA in the adult human visual cortex. Curr Biol 25:1496-1501. CrossRef Medline

Marenco S, Savostyanova AA, van der Veen JW, Geramita M, Stern A, Barnett AS, Kolachana B, Radulescu E, Zhang F, Callicott JH, Straub RE, Shen J, Weinberger DR (2010) Genetic modulation of GABA levels in the anterior cingulate cortex by GAD1 and COMT. Neuropsychopharmacology 35:1708-1717. Medline

Menon RS, Ogawa S, Strupp JP, Uǧurbil K (1997) Ocular dominance in human V1 demonstrated by functional magnetic resonance imaging. J Neurophysiol 77:2780-2787. Medline

Mescher M, Merkle H, Kirsch J, Garwood M, Gruetter R (1998) Simultaneous in vivo spectral editing and water suppression. NMR Biomed 11:266272. Medline

Morrone MC, Burr DC, Speed HD (1987) Cross-orientation inhibition in cat is GABA mediated. Exp Brain Res 67:635-644. Medline

Moult PR (2009) Neuronal glutamate and GABAA receptor function in health and disease. Biochem Soc Trans 37:1317-1322. CrossRef Medline

Mullins PG, McGonigle DJ, O'Gorman RL, Puts NA, Vidyasagar R, Evans CJ, Edden RA (2014) Current practice in the use of MEGA-PRESS spectroscopy for the detection of GABA. Neuroimage 86:43-52. CrossRef Medline

Murdoch JB, Dydak U (2011) Modeling MEGA-PRESS macromolecules for a better grasp of GABA. Proc Int Soc Magn Reson Med 19:1394.

Near J, Simpson R, Cowen P, Jezzard P (2011) Efficient $\gamma$-aminobutyric acid editing at $3 \mathrm{~T}$ without macromolecule contamination: MEGASPECIAL. NMR Biomed 24:1277-1285. CrossRef Medline

Near J, Andersson J, Maron E, Mekle R, Gruetter R, Cowen P, Jezzard P (2013) Unedited in vivo detection and quantification of $\gamma$-aminobutyric acid in the occipital cortex using short-TE MRS at 3 T. NMR Biomed 26:1353-1362. CrossRef Medline

Near J, Ho YC, Sandberg K, Kumaragamage C, Blicher JU (2014) Longterm reproducibility of GABA magnetic resonance spectroscopy. Neuroimage 99:191-196. CrossRef Medline

Nieder A, Dehaene S (2009) Representation of number in the brain. Annu Rev Neurosci 32:185-208. CrossRef Medline

Orban GA, Vogels R (1998) The neuronal machinery involved in successive orientation discrimination. Prog Neurobiol 55:117-147. CrossRef Medline

Perna A, Tosetti M, Montanaro D, Morrone MC (2005) Neuronal mechanisms for illusory brightness perception in humans. Neuron 47:645-651. CrossRef Medline

Picardo MA, Guigue P, Bonifazi P, Batista-Brito R, Allene C, Ribas A, Fishell G, Baude A, Cossart R (2011) Pioneer GABA cells comprise a subpopulation of hub neurons in the developing hippocampus. Neuron 71:695709. CrossRef Medline

Pinel P, Piazza M, Le Bihan D, Dehaene S (2004) Distributed and overlapping cerebral representations of number, size, and luminance during comparative judgments. Neuron 41:983-993. CrossRef Medline

Priebe NJ, Ferster D (2008) Inhibition, spike threshold, and stimulus selectivity in primary visual cortex. Neuron 57:482-497. CrossRef Medline

Ringach DL, Shapley RM, Hawken MJ (2002) Orientation selectivity in macaque V1: diversity and laminar dependence. J Neurosci 22:5639-5651. Medline

Roitman JD, Brannon EM, Platt ML (2007) Monotonic coding of numerosity in macaque lateral intraparietal area. PLoS Biol 5:e208. CrossRef Medline

Roitman JD, Brannon EM, Platt ML (2012) Representation of numerosity in posterior parietal cortex. Front Integr Neurosci 6:25. CrossRef Medline

Sandberg K, Blicher JU, Dong MY, Rees G, Near J, Kanai R (2014) Occipital GABA correlates with cognitive failures in daily life. Neuroimage 87:5560. CrossRef Medline

Sandberg K, Blicher JU, Del Pin SH, Andersen LM, Rees G, Kanai R (2016) 
Improved estimates for the role of grey matter volume and GABA in bistable perception. Cortex 83:292-305. CrossRef Medline

Schwartz O, Hsu A, Dayan P (2007) Space and time in visual context. Nat Rev Neurosci 8:522-535. CrossRef Medline

Shen J (2003) On the foundations of vision modeling: I. Weber's law and Weberized TV restoration. Physica D 175:241-251. CrossRef

Simpson R, Devenyi GA, Jezzard P, Hennessy TJ, Near J (2017) Advanced processing and simulation of MRS data using the FID appliance (FIDA) - an open source, MATLAB-based toolkit. Magn Reson Med 77:2333. CrossRef Medline

Smith MA, Bair W, Movshon JA (2006) Dynamics of suppression in macaque primary visual cortex. J Neurosci 26:4826-4834. CrossRef Medline

Somers DC, Nelson SB, Sur M (1995) An emergent model of orientation selectivity in cat visual cortical simple cells. J Neurosci 15:5448-5465. Medline

Song C, Schwarzkopf DS, Lutti A, Li B, Kanai R, Rees G (2013a) Effective connectivity within human primary visual cortex predicts interindividual diversity in illusory perception. J Neurosci 33:18781-18791. Nov CrossRef Medline

Song C, Schwarzkopf DS, Rees G (2013b) Variability in visual cortex size reflects tradeoff between local orientation sensitivity and global orientation modulation. Nat Commun 4:2201. CrossRef Medline

Song C, Schwarzkopf DS, Kanai R, Rees G (2015) Neural population tuning links visual cortical anatomy to human visual perception. Neuron 85: 641-656. CrossRef Medline

Stettler DD, Das A, Bennett J, Gilbert CD (2002) Lateral connectivity and contextual interactions in macaque primary visual cortex. Neuron 36: 739-750. CrossRef Medline
Swindale NV (2000) How many maps are there in visual cortex? Cereb Cortex 10:633-643. CrossRef Medline

Taniguchi H, He M, Wu P, Kim S, Paik R, Sugino K, Kvitsiani D, Kvitsani D, Fu Y, Lu J, Lin Y, Miyoshi G, Shima Y, Fishell G, Nelson SB, Huang ZJ (2011) A resource of Cre driver lines for genetic targeting of GABAergic neurons in cerebral cortex. Neuron 71:995-1013. CrossRef Medline

van Loon AM, Knapen T, Scholte HS, St John-Saaltink E, Donner TH, Lamme VA (2013) GABA shapes the dynamics of bistable perception. Curr Biol 23:823-827. CrossRef Medline

Vogels R, Orban GA (1986) Decision factors affecting line orientation judgments in the method of single stimuli. Percept Psychophys 40:7484. CrossRef Medline

Walsh V (2003) A theory of magnitude: common cortical metrics of time, space and quantity. Trends Cogn Sci 7:483-488. CrossRef Medline

Wolf F, Geisel T (1998) Spontaneous pinwheel annihilation during visual development. Nature 395:73-78. CrossRef Medline

Wu SM (2010) Synaptic organization of the vertebrate retina: general principles and species-specific variations. Invest Ophthalmol Vis Sci 51:12641274. CrossRef

Yacoub E, Harel N, Ugurbil K (2008) High-field fMRI unveils orientation columns in humans. Proc Natl Acad Sci U S A 105:10607-10612. CrossRef Medline

Yoon JH, Maddock RJ, Rokem A, Silver MA, Minzenberg MJ, Ragland JD, Carter CS (2010) GABA concentration is reduced in visual cortex in schizophrenia and correlates with orientation-specific surround suppression. J Neurosci 30:3777-3781. CrossRef Medline 